\title{
FORMAÇÃO CONTINUADA EM SERVIÇO DE PROFESSORES DE EDUCAÇÃO FÍSICA DE UMA ESCOLA PRIVADA DO INTERIOR DO ESTADO DE SÃO PAULO
}

\author{
Priscila Danielle Barbosa Almeida \\ Fundação Municipal de Educação e Cultura de Santa Fé do Sul, Santa Fé do Sul, São Paulo, Brasil \\ Helena Faria de Barros \\ Universidade do Oeste Paulista, Presidente Prudente, São Paulo, Brasil \\ Raimunda Abou Gebran \\ Universidade do Oeste Paulista, Presidente Prudente, São Paulo, Brasil \\ Marcos Vinicius Francisco \\ Universidade do Oeste Paulista, Presidente Prudente, São Paulo, Brasil
}

\begin{abstract}
Resumo
Esta pesquisa analisou o processo de formação continuada em serviço de professores de Educação Física de uma escola privada em uma cidade de pequeno porte do interior de São Paulo. A pesquisa é de natureza qualitativa, do tipo estudo de caso, e os procedimentos centraram-se na observação das sessões de estudo promovidas na escola, entrevistas com as gestoras e professores de Educação Física, análise do Projeto Político Pedagógico e dos planos de ensino dos professores do referido componente curricular. Os resultados apontaram que, embora munidas de boa intenção, as gestoras apresentaram uma compreensão biologicista e funcionalista da Educação Física escolar. Merece destaque ainda, a participação ativa dos professores nos espaços de formação continuada na escola e para além dela.
\end{abstract}

Palavras-chave: Formação Continuada em Serviço. Educação Física. Formação Docente.

\section{Introdução}

A formação de professores constitui-se resposta à necessidade premente de profissionalização posta pela complexidade da sociedade atual, sendo uma preocupação vivenciada em muitos países. As mudanças econômicas, sociais e ideológicas afetam o modo de vida das pessoas, bem como alteram as condições de trabalho profissional. Nessa dinâmica, a atuação dos professores está associada à qualidade da educação, e a formação continuada ganha um destaque crescente por parte das políticas de governo.

García e Vaillant (2012) afirmam que a formação docente abarca quatro etapas, ou seja, a experiência anterior de ensino dos aspirantes a docentes, a formação inicial em instituição especializada, a iniciação profissional em escolas para os principiantes e o desenvolvimento profissional contínuo. A presente investigação centrou-se na última dessas etapas, sobretudo em relação aos professores que atuam frente ao componente curricular de Educação Física. 
O principal objetivo do estudo foi analisar o processo de formação continuada em serviço de professores de Educação Física de uma escola privada de uma cidade de pequeno porte do interior do estado de São Paulo.

\section{A Formação Profissional em Educação Física e a Formação Continuada}

Sabe-se que o desenvolvimento profissional é imprescindível à melhoria do ensino e da vivência escolar, durante os anos de trabalho docente. García e Vaillant (2012) apontam que o desenvolvimento profissional transformou-se em condição sine qua non para qualquer profissão, incluindo a dos professores.

Vários termos são utilizados para designar este processo de formação docente continuada. García e Vaillant (2012) ressaltam que muitos o nomeiam como formação permanente, formação contínua, formação em serviço, desenvolvimento de recursos humanos, aprendizagem ao longo da vida, reciclagem, capacitação e formação continuada em serviço.

No presente trabalho assumem-se como sinônimos as expressões formação continuada em serviço e desenvolvimento profissional. No que tange a essas dimensões, Azevedo et al. (2010) e Heringer e Figueiredo (2009) apontam que, com uma influência muito intensa dos princípios da racionalidade técnica, a formação continuada ganhou força, em especial, a partir dos anos finais da década de 1970. Nesse contexto, criou-se o Comitê Nacional Pró-Formação do Educador, durante a I Conferência Brasileira de Educadores em São Paulo, corroborando inclusive com o aparecimento da Associação Nacional pela Formação dos Profissionais da Educação (ANFOPE), no ano de 1990. Essa discussão materializou-se num movimento em favor da docência como elemento constituinte da identidade profissional (HERINGER; FIGUEIREDO, 2009).

Com relação à Educação Física, Neto e Molina (2003) aclaram que, embora seja nos anos finais da década de 1970 que a área aderiu à política nacional de pós-graduação, suas produções, em termos de pesquisas, ficaram muito centradas no âmbito esportivo. No que diz respeito à Educação Física na educação básica, as lacunas ainda são presentes. Os impactos desse processo são percebidos nas dificuldades "para encaminhar uma formação profissional consistente que atenda as demandas sociais, porque essa formação está imersa em uma cultura docente com forte influência do diagnóstico, da prescrição, da normatização e da objetividade" (NETO; MOLINA, 2003, p. 266). Azevedo et al. (2010) complementam que a Educação Física ainda não conseguiu superar os limites de uma formação eminentemente técnica, destinada ao fazer. O refletir sobre o fazer ainda é pouco valorizado.

A dimensão do "como ensinar" é importante, mas insuficiente se não atrelada de forma dialética às demais dimensões que deverão ser contempladas na mediação dos conhecimentos das diferentes manifestações da cultura corporal. Torna-se imperioso abordar também na práxis pedagógica o "por quê", o "para quê" e "a serviço do que e de quem" se ensina.

Na mesma linha de análises, Figueiredo (2009) chama atenção para o fato de que os currículos de formação de professores em Educação Física ainda são normativos e utilitários. Daí a necessidade de se investir na formação qualificada de professores, seja em âmbito inicial ou na formação continuada, já que a intervenção docente dar-se-á mediante centenas de alunos que passarão por suas vidas ao longo da carreira profissional.

Azevedo et al. (2010) e Neto e Molina (2003) ressaltam que a formação profissional é um processo inacabado que se inicia antes da formação inicial e esta, por sua vez, não se encerra em si mesma, fazendo-se necessária a continuidade desse processo. Loureiro e Caparróz (2010) e Neto e Molina (2003) listam vários motivos que impulsionam os professores de Educação Física às experiências de formação continuada: a) a formação inicial não possibilitou elementos suficientes para o atendimento das demandas da prática profissional; b) as atividades de formação continuada oferecem oportunidades de progressão na carreira e obtenção de 
melhores salários; c) tais atividades possibilitam um novo rumo ao exercício profissional, elevando, em muitos casos, a autoestima do professorado; d) os professores utilizam-se dessas atividades para tratar de questões coletivas de ordem político-pedagógica, circunscritas à profissão.

Há que se ressaltar que os programas de formação continuada não devem ser vistos como processos técnicos e burocráticos, mas como "processos políticos que atendam ao interesse coletivo e possibilitem aos educadores compreender como as condições macroestruturais conduzem seu trabalho" (LOUREIRO; CAPARRÓZ, 2010, p. 33-34). Nessa dinâmica não basta oferecer apenas formação para o trabalho, mas é preciso integrá-la ao próprio trabalho (HERINGER; FIGUEIREDO, 2009).

Heringer e Figueiredo (2009, p. 92) apontam a ilogicidade de se pensar em uma ação formativa na qual o sujeito seja mero receptor de algo elaborado verticalmente para ele. Este parece ser elemento central para que alguns professores apresentem resistências às propostas de formação continuada, "que geralmente se constroem para e não com esses profissionais". Há também crítica à racionalidade instrumental que busca a eficiência na utilização de recursos disponíveis, como se esses estivessem numa relação de causalidade linear entre a eficácia da ação educativa e a eficácia da ação desenvolvida pelo professor.

Defende-se, a partir de Azevedo et al. (2010), que a formação continuada do professor tenha como base a prática pedagógica e abarque como finalidade dessa prática o incentivo para que os docentes compreendam a importância e a significação dos conhecimentos produzidos historicamente pela humanidade. Daí a necessidade de se contemplar a dimensão coletiva em âmbito teórico, pedagógico e educacional, nesse tipo de formação, a fim de ampliar as compreensões dos professores sobre suas formas de ensino, vislumbrando-se as transformações do contexto no qual se encontram imersos.

Nóvoa (2013) ressalta a necessidade de se garantir uma efetiva formação continuada, bem como a necessidade premente da fusão dos espaços acadêmicos e institucionais das escolas para a formação do professor. Defende assim a criação de nova realidade organizacional no interior da escola em que estejam integrados os professores (da rede) e os formadores ( $u-$ niversitários).

Loureiro e Caparróz (2010, p. 24) reforçam que o distanciamento entre o universo acadêmico-universitário e o âmbito escolar é apontado como um importante fator no que concerne à formação continuada, pari passu os professores que atuam nas escolas percebem "que a produção teórico-acadêmica não tem considerado a complexidade da realidade escolar na qual se materializam as práticas pedagógicas da área”. Os professores da educação básica precisam ser reconhecidos como parceiros/pesquisadores desse processo.

\section{Aspectos metodológicos}

Esta pesquisa é de natureza qualitativa, do tipo estudo de caso. A pesquisa qualitativa, de acordo com Santos Filho e Gamboa (1997), rejeita a possibilidade de descoberta de leis sociais e centra-se na interpretação do fenômeno social, a partir das perspectivas dos participantes. Para Minayo (2010), nesse tipo de abordagem, deve prevalecer a capacidade de o pesquisador identificar e analisar profundamente dados não mensuráveis, tais como as percepções, os pensamentos, as opiniões e os significados de um determinado grupo de pessoas.

Em relação ao estudo de caso, Severino (2007) aponta que:

[...] se concentra no estudo de um caso particular, considerado representativo de um conjunto de casos análogos, por ele significativamente representativo. [...] o caso escolhido para a pesquisa deve ser significativo e bem representativo, de modo a ser apto a fundamentar uma generalização para situações análogas, autorizando inferências. (SEVERINO, 2007, p. 121). 
O autor pondera que, no estudo de caso, os dados devem ser coletados e registrados com o necessário rigor, seguindo todos os procedimentos da pesquisa de campo.

\section{Seleção da escola}

Buscou-se uma escola privada que estava desenvolvendo ações de formação continuada com seus professores, de modo sistematizado e organizado, em um município de pequeno porte do interior do estado de São Paulo. Para tanto, ao fazer o levantamento das escolas do referido município, constatou-se, por meio das respectivas direções escolares, que apenas uma delas se adequava ao perfil selecionado, por apresentar um plano em execução de formação continuada. A instituição proporcionava atividades de formação continuada, semanalmente, há 25 anos, aos professores. Vale apontar que a escola é premiada nacionalmente pelo desempenho como instituição de ensino.

\section{Participantes da pesquisa}

Diante dos objetivos da investigação, participaram da pesquisa os dois professores de Educação Física da escola, as quatro coordenadoras pedagógicas e a diretora pedagógica. A seleção das coordenadoras pedagógicas, bem como da diretora pedagógica, justificou-se diante da premissa de que elas eram responsáveis diretas pelos espaços de formação continuada dos professores de Educação Física. Posto a amostra da pesquisa, o grupo constituiu-se por profissionais do sexo masculino e feminino. A faixa etária dos participantes variava entre 29 e 61 anos. As diferentes áreas de formação dos profissionais eram Licenciatura Plena em Educação Física, Pedagogia e Direito, com diferentes níveis de titulação, conforme apresentado no quadro 01 .

QUADRO 1 - Formação Acadêmica dos participantes da pesquisa

\begin{tabular}{|l|l|c|}
\hline CARGO & \multicolumn{1}{|c|}{ GRADUAÇÃO } & $\begin{array}{c}\text { PÓS- } \\
\text { GRADUAÇÃo }\end{array}$ \\
\hline Professor & Educação Física & Especialização \\
\hline Professor & Educação Física & Especialização \\
\hline Coordenadora & Direito & Especialização \\
\hline Coordenadora & Pedagogia & Especialização \\
\hline Coordenadora & Pedagogia & Especialização \\
\hline Coordenadora & Educação Física e Pedagogia & Especialização \\
\hline Diretora & Pedagogia & Mestrado \\
\hline
\end{tabular}

Fonte: Pesquisa de campo, 2014.

Vale apontar que os Termos de Consentimento Livre Esclarecidos (TCLE) foram entregues a todos os participantes, a fim de que eles pudessem consentir sua participação na pesquisa. A investigação obteve aprovação junto ao Comitê de Ética em Pesquisa e respeitou todos os procedimentos da pesquisa com seres humanos.

\section{Fases da pesquisa de campo}

Inicialmente, observou-se oito encontros de formação continuada desenvolvidos semanalmente, pela escola, que promoviam estudos e organização das atividades pedagógicas e 
administrativas ligadas diretamente aos alunos. As observações foram registradas num diário de bordo, de acordo com o seguinte roteiro: as ações dos professores, os temas dos encontros, liderança dos encontros e a reação dos docentes de Educação Física mediante as discussões abordadas.

Posteriormente, foram realizadas entrevistas semiestruturadas com todos os participantes, com a intenção de averiguar a importância dada ao processo de formação continuada em serviço pelos gestores e professores de Educação Física e como eles aplicavam os conhecimentos decorrentes desse processo em seu dia a dia. As entrevistas tiveram duração média de 30 minutos e foram gravadas. Após esse processo, foram transcritas, facilitando o processo de categorização e análise dos dados.

Em seguida, analisou-se o Projeto Político Pedagógico da escola, na expectativa de verificar como essas reuniões de formação continuada em serviço eram contempladas no referido documento. Além disso, procedeu-se pela análise dos planos de ensino dos dois professores de Educação Física, conforme orientações de Laville e Dionne (1999).

$\mathrm{O}$ conteúdo coletado nas diferentes fases da pesquisa foi categorizado, a fim de dar significado aos dados e, assim, ratificá-los. Na primeira categoria intitulada "A importância concedida à disciplina de Educação Física pela equipe gestora da escola", apresentou-se a opinião das gestoras frente ao referido componente curricular; a percepção delas em relação à participação dos professores de Educação Física nos espaços de formação, além de seus impactos à escola e à sociedade; e o que faziam para estimular a participação ativa desses docentes. A segunda categoria, "A participação dos professores de Educação Física nos espaços de formação continuada", apresenta a perspectiva dos docentes com relação à formação recebida; se buscam outros espaços de formação para além dos muros escolares e como percebem os impactos da formação continuada na práxis-pedagógica.

\section{Análise dos dados e discussão}

Categoria 1 - A importância concedida à disciplina de Educação Física pela equipe gestora da escola

Nas entrevistas com as gestoras, um dos aspectos averiguados centrou-se na visão que elas têm acerca do componente curricular de Educação Física no processo de ensino e aprendizagem dos alunos. Ficou evidenciada uma compreensão biologicista e funcionalista do referido componente, como se o mesmo estivesse circunscrito apenas à dimensão de um corpo deslocado espacialmente e historicamente. Essa visão reflete os discursos do senso-comum que a área ainda não conseguiu desmobilizar, conforme já destacado (AZEVEDO et al., 2010). Apresentam-se alguns exemplos de falas:

A Educação Física é extremamente importante, pois colabora muito no desenvolvimento da motricidade dos grandes e pequenos músculos, assim como em todo desenvolvimento biopsicomotor da criança, e todos os exercícios com o corpo fazem bem à saúde. (GESTORA, 1).

A Educação Física é importante porque o desenvolvimento da criança exige movimento, estímulo e socialização para que sua vida desenvolva tanto no aspecto biológico quanto para criar habilidades de controle e coordenação, força e agilidade em diferentes atividades. (GESTORA, 2).

É de extrema importância, principalmente nesta era virtual, que nossos adolescentes crescem sem sequer praticar um esporte, não gostam de se 
mexer. É muito bom os professores dessa área orientá-los e estimulá-los a terem uma vida mais saudável com a ajuda da Educação Física. (GESTORA, 3).

Percebeu-se, nas falas das gestoras 1 e 2, certa ênfase na motricidade e na coordenação motora dos alunos. A terceira gestora, embora preconizou umas das dimensões da área, ou seja, os aspectos ligados à promoção da saúde, também não conseguiu visualizar o componente curricular de maneira ampla. Por conseguinte, não há um entendimento da função social da Educação Física, como uma disciplina capaz de colocar os alunos em contato com as diferentes manifestações da cultura corporal, a fim de que eles possam agir de forma autônoma e crítica, compreendendo a cultura na qual se encontram inseridos (BRACHT, 2001; SOARES et al., 1992). Bracht (2001) deixa claro que toda concepção biológica sobre o corpo precisa ser superada por uma visão na qual o corpo possa ser redescoberto:

[...] ou descoberto como sujeito histórico, no sentido do reconhecimento de sua importância para entender o processo histórico. As ações sobre ele precisam figurar na trama histórica, isto é, as ações sobre o corpo são importantes para se entender o processo histórico; a história do homem é também uma história do controle do corpo, das ações sobre ele. Outro aspecto importante é o reconhecimento da importância ontológica do corpo, portanto, para o entendimento do próprio homem, recuperando, assim, para a sensibilidade, para a dimensão sensível ou estética, prestígio em frente à razão. O corpo, que sempre foi hierarquicamente secundarizado diante da razão, parece começar a recuperar [...] certa dignidade ontológica. (BRACHT, 2001, p. 74).

Ainda, com um caráter generalista, a fala da gestora 5 foi a que mais valorizou a disciplina de Educação Física, ao colocá-la em pé de igualdade dos demais componentes curriculares:

A Educação Física é tão importante quanto qualquer outra área do currículo, tão importante quanto Português ou Matemática, por exemplo. (GESTORA, $5)$.

Esse é um movimento muito presente nas representações da população sobre as funções da Educação Física escolar, ao passo que alguns reconhecem um pouco mais as especificidades da área, enquanto outros ainda estão presos em visões completamente distorcidas do componente curricular. Esse cenário, ainda, é reflexo de lacunas que a área apresenta, visto que suas produções científicas e a formação profissional ainda se encontram fortemente pautadas no âmbito esportivo (AZEVEDO et al., 2010; NETO; MOLINA, 2003) e nos discursos que enfatizam a saúde de maneira desarticulada dos aspectos sociais, políticos e econômicos.

Quando perguntado às gestoras como a escola e a sociedade se beneficiam da atuação dos professores que participam dos espaços e momentos de formação continuada, sobretudo, os da área de Educação Física, elas apontaram:

O professor atualizado traz para as aulas atividades problematizadas, desafios contextualizados, suas aulas são interdisciplinarizadas com os conteúdos trabalhados pelas outras disciplinas em sala de aula, tornando as aulas mais atrativas e interessantes para os alunos. (GESTORA, 1).

Um professor bem atualizado beneficia os alunos e a escola, transmite por meio das atividades valores éticos, além de melhorar funções 
metabólicas e conscientizar os educandos da importância do cuidado com o corpo, buscando uma convivência solidária. (GESTORA, 2)

A escola terá alunos mais dinâmicos e a sociedade uma população mais saudável. (GESTORA, 3).

Com esse profissional saberão mais sobre prática de exercícios, estímulo ao esporte, desenvolvimento do aspecto artístico e promover a saúde corporal. (GESTORA, 4).

As aulas de Educação Física na escola são diferentes das brincadeiras que acontecem em casa ou no clube. Elas ensinam como a criança deve se mover, contribuem para o desenvolvimento físico e mental, estimulam o crescimento psicomotor, entre outros benefícios. Sendo assim, apenas um professor de Educação Física atualizado em suas práticas poderá ter esse olhar e não compactuar com a ideia de que Educação Física é só recreação. (GESTORA, 5).

As respostas das gestoras 2, 3 e 4 congregaram com uma visão mecânica do processo de formação continuada dos professores ao relacionarem que os benefícios para a escola e comunidade estão pautados no universo da promoção de saúde, como se apenas as aulas deste componente curricular fossem suficientes. Não se trata de negar tal dimensão, até mesmo porque a área apresenta um espectro mais amplo de conteúdos (SOARES et al., 1992). Todavia, não há como pensar em saúde sem considerar as condições materiais e objetivas dadas socialmente em uma determinada realidade (BAGRICHEVSKY; PALMA; ESTEVÃO, 2003). As classes menos favorecidas, por exemplo, sempre estarão em desvantagem na promoção da saúde por meio da atividade física, se comparado às pessoas com melhores situações econômicas. Até mesmo aqueles que têm condições econômicas para praticar atividades físicas, acabam permanecendo em estado de sedentarismo, em função das excessivas jornadas de trabalhos a que estão submetidos, aliados aos cuidados da casa e das obrigações familiares (PALMA, 2001). Estes são aspectos que precisam ser refletidos e discutidos pela área de Educação Física escolar.

Por outro lado, as falas das participantes 1 e 5 foram mais abrangentes, ao focarem, inclusive, na problematização das aulas, de forma interdisciplinar com a intenção de que elas sejam mais interessantes para os alunos e professores, ou num entendimento de que a Educação Física ultrapasse a concepção de que é um momento de recreação (SOARES et al., 1992).

Outro aspecto das entrevistas referiu-se ao que as gestoras fazem para estimular a formação continuada em serviço de seus professores de Educação Física. As respostas explicitaram um perfil tradicional de formação continuada, pois a maioria delas mencionou apenas os encontros de Aulas de Trabalho Pedagógico Coletivo (ATPC), realizados semanalmente e obrigatórios na escola.

No início do ano já fica combinado com os professores (no ato do contrato) que duas horas/aulas por semana, ou seja, as ATPCs são destinadas para as capacitações, que ocorrem todas as terças-feiras. (GESTORA, 1).

Estímulo, dando a eles recursos necessários para o desenvolvimento das aulas e discutindo assuntos que visem melhorar a aprendizagem 
dos educandos e ampliar as atividades desenvolvidas pelos docentes. (GESTORA, 2).

Oferecendo materiais necessários para suas aulas serem dinâmicas e atrativas com qualidade, não esquecendo de oferecer reportagens e artigos que comentem ideias para suas aulas, fazendo com que o professor esteja se atualizando sempre. (GESTORA, 3).

Reunião de Capacitação nas ATPCs. (GESTORA, 4).

Realizamos estudos semanais com todos os professores nas ATPCs, ou seja, é um horário de estudo coletivo com a perspectiva interdisciplinar. (GESTORA, 5).

As falas denunciam que a formação continuada oferecida é insuficiente, ao passo que muito mais do que uma instrumentalização para as aulas, os professores devem compreender a importância e utilidade dos conhecimentos produzidos histórica e culturalmente pela humanidade (AZEVEDO et al., 2010). Loureiro e Caparróz (2010) fazem severa crítica aos programas de formação continuada que se debruçam maciçamente em processos técnicos e burocráticos. Mais do que isso, os programas precisam assumir a característica de serem almejados como processos políticos que atendam aos interesses da coletividade. Prossegue Heringer e Figueiredo (2009), afirmando que mais do que oferecer formação para o trabalho é preciso integrá-la ao próprio trabalho.

Corroboram com essas falas, as observações das sessões de estudo realizadas semanalmente. Elas ocorreram na própria escola, e embora servissem para apresentar/promover vários projetos coletivos desenvolvidos pelos professores da escola, eles não emergiram diretamente dos professores ou de suas necessidades, além de não preconizarem relações com o contexto social mais amplo, ficando muitas vezes presos a dimensão burocrática de funcionamento da instituição.

Tais aspectos contrariam o que Nóvoa (2013) defende, pois os próprios professores precisam assumir o protagonismo acerca dos conhecimentos profissionais necessários à capacitação de seus pares. Nessa lógica, deverá ser criado um espaço favorecedor do diálogo entre a realidade vivenciada nas/pelas escolas e o conhecimento científico-acadêmico, a fím de se solucionar os problemas cotidianos.

Como exemplo, menciona-se a segunda sessão de estudos, coordenada pela diretora da instituição. Os assuntos da pauta relacionaram-se aos aspectos organizacionais e aos aspectos pedagógicos, embora, maciçamente, a sessão tenha ficado circunscrita aos aspectos organizacionais: a) disposição das carteiras em sala de aula; b) limpeza da sala ao final de cada aula; c) cumprimento dos horários pelos alunos e professores; d) alunos sem material não poderão assistir a aula; e) proibição do uso do celular em aula. No que tange aos aspectos pedagógicos, a diretora enfatizou maior atenção dos docentes à aprendizagem dos alunos e à realização de tarefas extraclasse, além de mencionar a importância de um trabalho coletivo entre professores e coordenação pedagógica. Contudo, nenhuma leitura científico-acadêmica subsidiou tais discussões no dia. Elas foram pautadas, fundamentalmente, em posicionamentos pessoais da gestora.

Essa dimensão presente nos espaços de formação continuada contraria um aspecto do Projeto Político Pedagógico da instituição, tendo vista a sinalização de que: 
"[...] a abertura inicial de uma nova concepção deve ser acompanhada de um conjunto de práticas correlatas e da reflexão sobre elas" (PROJETO POLÍTICO PEDAGÓGICO DA ESCOLA).

Ao preconizar a ênfase na mudança e reflexão da ação docente, via formação continuada, o Projeto Político Pedagógico revela uma intencionalidade que ultrapassa a perspectiva meramente técnica e instrumental. Entretanto, verificou-se que isso não se efetivou no contexto da escola, no que se refere aos momentos de formação.

Categoria 2 - A participação dos professores de Educação Física nos espaços de formação continuada

Ao analisar os encontros de formação continuada desenvolvidos semanalmente pela escola, percebeu-se a participação ativa dos professores de Educação Física nas atividades e discussões propostas pelas gestoras da escola. Em linhas gerais, tais encontros focaram nas questões burocráticas, organizacionais, didáticas e pedagógicas das aulas e da escola. Um aspecto que chamou atenção referiu-se às discussões sobre projetos integradores, sendo que os docentes sempre participaram juntos das demais disciplinas, como já sinalizado.

Apresenta-se como exemplo, o terceiro encontro, no qual uma das coordenadoras pedagógicas explanou sobre a necessidade de a escola desenvolver um projeto integrador de "Educação para a Paz", a fim de coibir os casos de violência entre os estudantes. Após essa fala, a professora de Educação Física do $1^{\circ}$ ano do Ensino Fundamental, mencionou ao grupo de professores certo grau de dificuldade ao lidar com três alunos que apresentavam problemas de relacionamento interpessoal em suas aulas, acrescido ao fato de que não sabia como agir mediante tais situações, já que eles prejudicavam o bom andamento das atividades planejadas. A professora de Ciências indicou à professora de Educação Física que ela tentasse promover jogos cooperativos com a turma, na expectativa de que pudesse problematizar que nesse tipo de atividades a participação coletiva é fundamental. A professora achou interessante e assumiu perante o grupo tal compromisso.

Nesse caso, em específico, no encontro subsequente foi possível constatar que a professora de Educação Física já havia desenvolvido algumas atividades cooperativas, tais como: "Que não caia" e "Varrer balões", conforme seu relato. Ela mencionou que a aula apresentou rendimento satisfatório, visto que os alunos se relacionaram melhor. As atividades, inicialmente, foram propostas para serem realizadas em trios, sendo que a professora colocou os alunos com problemas de relacionamentos interpessoais nos mesmos grupos. Mencionou ainda que, ao final das atividades, combinou com os alunos que continuariam vivenciando mais atividades cooperativas nas próximas aulas.

Ressalta-se a importância e a significação dessas atividades que, ao minimizar as ocorrências de violência escolar entre os alunos, possibilitaram maior interação entre eles. Essa proposição ratifica o posicionamento das gestoras sobre a necessidade de os professores planejarem aulas mais interativas e alinhadas às intencionalidades do contexto escolar, configurando-se em práticas integradoras e colaborativas.

Porto (2004, p. 15) reforça que, atualmente, ganha ênfase a defesa de que a escola deve ser entendida como "espaço de iniciativa e concretização de seus próprios projetos, exigindo, consequentemente, que suas práticas guiadas pela reflexão crítica, transformem-se em práxis medida pelo coletivo dos agentes educativos que nela atuam".

Perguntado aos professores em quais momentos eles mais utilizavam as atividades pedagógicas sugeridas nos encontros de formação, obteve-se resposta uníssona que eram utilizadas em todos os momentos, refletindo, inclusive, na organização, na execução e avaliação 
das aulas. Como exemplo, destacaram-se as respostas dos professores do componente curricular de Educação Física:

Eu utilizo em todos os campos, na programação, na organização, na execução e na avaliação, de acordo com as necessidades advindas do momento. (PROFESSOR, 1).

Em todos os processos. Com destaque maior para a organização (planejamento). (PROFESSOR, 2).

É notório reconhecer que muitas das ações presentes nos planejamentos feitos pelos professores eram decorrentes de discussões ocorridas nos encontros de formação, algo que transcendia às proposições apresentadas nos Planos de Ensino do componente curricular de Educação Física. Ao analisar esses documentos, constatou-se pouca ênfase sobre o trabalho com projetos coletivos e integradores, que se constituíram num avanço da práxis pedagógica.

Libâneo (1994, p. 222) pondera que os Planos de Ensino caracterizam-se como "a previsão dos objetivos e tarefas do trabalho docente para um ano ou um semestre; é um documento mais elaborado, no qual aparecem objetivos específicos, conteúdos e desenvolvimento metodológico". Esse distanciamento do que vem sendo desenvolvido nas aulas de Educação Física, em oposição ao que se encontrava registrado nos Planos de Ensino, conduz a uma interpretação que corrobora com as análises empreendidas por Salermo, Vieira e Botareli (2008, p. 56), ou seja, "o plano não deve ser considerado como algo pronto e acabado, mas, precisa ser caracterizado como um processo ordenado e passível de revisão, tanto por aqueles que o concebem como por aqueles que o colocam em ação".

Embora algumas críticas foram apresentadas na categoria anterior no que se refere aos conteúdos dos encontros de formação, reconhece-se que eles favorecem o desenvolvimento profissional e a atuação docente. García e Vaillant (2012) reiteram o quanto esse desenvolvimento faz-se necessário à melhoria do ensino e da vivência escolar.

A crítica aos conteúdos fundamenta-se em Azevedo et al. (2010), que salientam que a boa formação continuada não deve ficar circunscrita à aprendizagem de conteúdos, mas de um efetivo processo de reflexão pedagógica a ser consolidada diariamente. Dessa forma, a formação continuada deve ultrapassar uma visão técnica e "contribuir para a mudança educacional e para a redefinição da profissão docente" (NÓVOA, 2002, p. 38). O autor ainda afirma que o espaço da formação continuada não se configura como uma ação isolada do professor, mas sim como a sua inserção num corpo profissional e numa organização escolar, sendo que “deve estar finalizada nos 'problemas a resolver', e menos em 'conteúdos a transmitir', o que sugere a adopção de estratégias de formação-acção-organizacional” (NÓVOA, 2002, p. 40).

Outro aspecto a destacar refere-se ao questionamento que averiguou se os professores buscavam outros espaços de formação continuada para além dos encontros desenvolvidos na escola.

Sim, busco aperfeiçoamento. No Estado temos vários cursos de formação continuada, e todos os anos faço algum, como por exemplo, em 2012, fiz o curso de Inclusão em Educação Física, foi ótimo, com conhecimentos e práticas. Cursos de pós-graduação e aperfeiçoamento. (PROFESSOR, 1).

Sim, pós-graduação (especialização e mestrado), congressos e cursos de extensão em diversas áreas da Educação Física e gestão de pessoas. (PROFESSOR, 2). 
As falas dos professores culminaram com um dos aspectos apresentados por Loureiro e Caparróz (2010) e Neto e Molina (2003), ou seja, os professores motivam-se pela formação continuada como uma forma de se aperfeiçoarem em aspectos ligados às demandas da profissão em sua atuação. Nessa lógica, ultrapassa-se a concepção de que a formação continuada para além dos muros escolares refere-se à acumulação de cursos.

Por fim, reitera-se a partir de Rossi e Hunger (2012) que:

A formação continuada vem procurando caminhos de desenvolvimento de renovação. Está deixando de ser concebida na perspectiva da acumulação de cursos, conhecimentos ou técnicas e passando a ser concebida como um processo de reflexão das práticas de (re)construção permanente de uma identidade pessoal e profissional. (ROSSI; HUNGER, 2012, p. 326).

Esse processo de reconstrução da identidade pessoal e profissional via formação continuada pode, ainda, favorecer um movimento mais amplo de troca de experiência entre os professores de uma dada escola/segmento. Reitera Imbernón (2010) que, para além desse aspecto, há a atualização em todos os campos de intervenção educacional.

É preciso que, num esforço sistemático e contínuo, as mudanças garantam à escola constituir-se em uma comunidade de aprendizagem. As condições internas das escolas precisam ser redimensionadas, de modo que elas possam "planejar metas e estratégias de desenvolvimento para institucionalizar a aprendizagem contínua como forma de trabalho dos professores". (GARCÍA; VAILLANT, 2012, p. 49).

Em linhas gerais, a formação continuada em serviço assume que a escola é o lugar apropriado à formação de professores. Ela é um importante espaço de análise coletiva e compartilhada das práticas docentes. Os professores precisam assumir suas responsabilidades na formação de seus pares. Nessa perspectiva, a análise crítica das dificuldades surgidas na rotina de cada professor, mediante o contato com o conhecimento científico, deve constituir o objeto de estudo de todos.

\section{Considerações finais}

Esta pesquisa, por meio do estudo de caso, analisou o processo de formação continuada em serviço de professores de Educação Física de uma escola privada de uma cidade de pequeno porte do interior do estado de São Paulo. Embora munidas de boa intenção, na maioria dos momentos, as gestoras apresentaram uma compreensão biologicista e funcionalista da Educação Física escolar, como se a mesma fosse restrita à dimensão de um corpo deslocado espacialmente e historicamente. Muitos dos discursos e ações por parte destas profissionais estão arraigados no senso comum, os quais a área ainda não conseguiu desmobilizar, mesmo diante dos avanços na produção de conhecimentos científicos nas últimas décadas.

As respostas das gestoras explicitaram, ainda, uma concepção tradicional de formação continuada, sendo que a maioria delas mencionou apenas os encontros semanais de Aulas de Trabalho Pedagógico Coletivo (ATPC), realizados obrigatoriamente na escola. Corroboram com essas falas, as observações das sessões de estudo realizadas. Embora servissem para apresentar/promover vários projetos coletivos que foram desenvolvidos pelos professores da escola, eles não emergiram diretamente dos professores ou de suas necessidades, além de não preconizarem relações com o contexto social mais amplo, ficando muitas vezes presas à dimensão burocrática de funcionamento da instituição.

Merece destaque a participação ativa dos professores de Educação Física nas atividades e discussões propostas pelas gestoras da escola. Esse é um cenário que vem mudando nas 
últimas décadas, se comparado ao tempo em os professores, em várias escolas, sequer eram envolvidos nos espaços de discussões pedagógicas.

E mesmo diante das críticas ao como os encontros de formação continuada foram desenvolvidos, reconheceu-se o compromisso dos docentes, por meio de seus planos de ensino, na busca pelo desenvolvimento e aplicação de atividades/projetos integradores discutidos em tais espaços. Por fim, reconheceu-se que esse é um movimento inicial porque muito mais do que executar tarefas verticalizadas, os docentes precisam ser envolvidos numa formação que oportunize uma transformação contínua de sua práxis pedagógica, bem como do ambiente no qual se encontram inseridos.

\title{
CONTINUING EDUCATION IN SERVICE TEACHER OF PHYSICAL EDUCATION AT A PRIVATE SCHOOL IN THE STATE OF SÃO PAULO
}

\begin{abstract}
This research analyzed the process of continuing education in-service teacher of Physical Education at a private school in a small town in the interior of São Paulo. The research is qualitative in nature, the case study type and procedures focused on the observation of study sessions promoted at school, interviews with the management and teachers of Physical Education and the Pedagogical Political Project analysis and lesson plans for teachers of that curriculum component. The results show that, although provided with good intentions, management presented a biologicist and functionalist understanding of the Physical Education. Noteworthy also the active participation of teachers in the areas of continuing education at school and beyond.
\end{abstract}

Keywords: Continuing Education in Servisse. Physical Education. Teacher Training.

\section{LA FORMACIÓN CONTINUA EN SERVICIO DE MAESTROS DE LA EDUCACIÓN FÍSICA EN UNA ESCUELA PRIVADA EN EL ESTADO DE SÃO PAULO}

\section{Resumen}

Esta investigación analiza el proceso de formación continua de maestros en servicio de la Educación Física en una escuela privada en una pequeña ciudad del interior de São Paulo. La investigación es de carácter cualitativo, del tipo estudio de caso y los procedimientos se centrarón en la observación de las sesiones de estudio promovidos en la escuela, entrevistas con la dirección y los profesores de Educación Física, análisis del Proyecto Político Pedagógico y de los planes de lecciones para maestros de ese componente curricular. Los resultados muestran que, aunque siempre con buenas intenciones, la dirección presentó una comprensión biologicista y funcionalista de la Educación Física. Cabe destacar también la participación activa de los docentes en la formación continua en la escuela y más allá.

Palabras clave: Educación Continua en el Servicio. Educación Física. La Formación del Profesorado.

\section{Referências}

AZEVEDO, A. M. P. et al. Formação continuada na prática pedagógica: a Educação Física em questão. Movimento, Porto Alegre, v. 16, n. 04, p. 245-262, out./dez., 2010. 
BAGRICHEVSKY, M.; PALMA A.; ESTEVÃO A. A saúde em debate na Educação Física escolar. Blumenau: Editora Edibes, 2003.

BRACHT, V. Saber e fazer pedagógicos acerca da legitimidade da Educação Física como componente curricular. In: CAPARRÓZ, F. E. Educação Física escolar: política, investigação e intervenção. Vitória-ES: Proteoria, 2001, p.67-79.

FIGUEIREDO, Z. C. Uma experiência de formação de professores de Educação Física na perspectiva do formar-se professor. Pensar a Prática, Goiânia, v.12, n.3, p.1-11, set./dez., 2009.

GARCÍA, C. M; VAILLANT, D. Ensinado a ensinar: as quatro etapas de uma aprendizagem. Curitiba: UTFPR, 2012.

HERINGER, D.; FIGUEIREDO, Z. Práticas de formação continuada em Educação Física. Movimento, Porto Alegre, v.15, n.04, p.83-105, out./dez., 2009.

IMBERNON, F. Formação continuada de professores. Porto Alegre: Artmed, 2010.

LAVILLE, C.; DIONNE, J. A construção do saber: manual de metodologia da pesquisa em ciências humanas. Porto Alegre: Artmed,1999.

LIBÄNEO, J. C. Didática. 21 ed. São Paulo: Cortez, 1994.

LOUREIRO, W.; CAPARRÓZ, F. E. O imaginário social de professores de Educação Física na rede municipal de ensino de Vitória a respeito de sua formação continuada. Revista Brasileira de Ciências do Esporte, Campinas, v.31, n.3, p.23-42, mai./ago., 2010.

MINAYO, M. C. S. (Org.). Pesquisa social: teoria, método e criatividade. 29 ed. Rio de Janeiro: Vozes, 2010.

NETO, V. M.; MOLINA, R. M. K. Identidade e perspectivas da Educação Física na América do Sul: formação profissional em Educação Física no Brasil. In: BRACHT, V.; CRISORIO, R. A Educação Física no Brasil e na Argentina: identidades, desafios e perspectivas. Campinas: Autores Associados; Rio de Janeiro: PROSUL, 2003, p.259-278.

NÓVOA, A. A formação contínua entre pessoa-professor e a organização-escola. In: NÓVOA, A. (Org.). Formação de professores e trabalho pedagógico. Lisboa: Educa, 2002, p. $31-48$.

NÓVOA, A. Três bases para um novo modelo de formação. Gestão escolar, n. 27, p.52-55, ago/set., 2013.

PALMA, A. Educação Física, corpo e saúde: uma reflexão sobre outros "modos de olhar". Revista Brasileira de Ciências do Esporte, Campinas, v. 22, n. 2, p. 23-39, jan. 2001.

PORTO, Y. S. Formação continuada: a prática pedagógica recorrente. In: MARIN, A. J.

(Org.). Educação continuada: reflexões, alternativas. 2 ed. Campinas: Papirus, 2004. p. 11 38 . 
ROSSI, F.; HUNGER, D. As etapas da carreira docente e o processo de formação continuada de professores de Educação Física. Revista Brasileira de Educação Física e Esporte, São Paulo, v. 26, n. 2, p. 23-38, abr./jun., 2012.

SALERMO, S. C. E. K.; VIEIRA, E. M.; BOTARELI, D. S. Planejamento escolar reflexões acerca de sua materialidade. Unopar Científica: Ciências Humanas e Educação, Londrina, v. 13, n. 1, p. 53-59, jun. 2012.

SANTOS FILHO, J. C.; GAMBOA, S. S. (Orgs.). Pesquisa educacional: quantidadequalidade. $2^{a}$ ed. São Paulo: Cortez, 1997.

SEVERINO, A. J. Metodologia do trabalho científico. 23 ed. São Paulo: Cortez, 2007.

SOARES, C. L. et al. Metodologia do Ensino de Educação Física / Coletivo de Autores. $2^{\text {a }}$ ed. São Paulo, SP: Cortez, 1993.

Recebido em: 27/02/2016

Revisado em: 18/04/2016

Aprovado em: 01/09/2016

Endereço para correspondência:

marcos_educa01@yahoo.com.br

Marcos Vinicius Francisco

Universidade do Oeste Paulista

Rua José Bongiovani, 700

Cidade Universitária

Presidente Prudente - SP, 19050-920 